\title{
Lingu-Didactical Basis Of Teaching English Learning Vocabulary To The First-Year Uzbek Audience Students
}

\author{
Tashtemirova Mufassal Alidjanovna, Kharatova Shakhlo Khakimovna, Tulaboeva Gulorom \\ Tulaboevna, Akhmatova Khalida Shukurovna, Utashev Kuldash Xafizovich \\ Department of Foreign languages-1, Tashkent State Transport University, Tashkent, Uzbekistan.
}

\begin{abstract}
The relevance of the study is that the academic work is devoted to one of the least researched linguistic problems, the importance of teaching the English language teaching vocabulary to the students of the first year Uzbek audience and the solution of the problems. Effective teaching of English requires students to communicate as much as possible in English. Naturally, students learn a foreign language mainly in an educational institution, and therefore, the full understanding and application of the teaching lexicon in the educational process is one of the pressing problems. The research subject is the process of teaching the English Language Teaching lexicon to the students in the Uzbek audience. The scientific novelty of the study includes the following: 1) comparison of the composition of the Uzbek and English Language Teaching lexicon in the dissertation; 2) detailed identification of similarities and differences between the Uzbek and English Language Teaching lexicon; 3) description of the state of interpersonal interaction in the Uzbek and English language lexicon system on the basis of clear and concise materials; 4) the system of assignments is designed to eliminate the negative cases of interference in the teaching of the English Language Teaching lexicon to Uzbek students.
\end{abstract}

\section{Introduction}

To study theoretical and practical issues of Science in Uzbekistan, in particular, comparative linguistics and methodology of teaching foreign languages, as well as interfaith D.Buronov, M.Dzhosupav, J.Jalalov, G. Antrushina, G. Tightly, H. Seynazarov, M. Stepanova, I. Galperin, V. The contributions of such scientists as Nikonov are huge. Scientific research conducted by these well-known scientists and published textbooks and manuals are being programmed in our country to deeply master foreign languages. However, the implementation of scientific achievements in the practice of teaching foreign languages has not yet been fully resolved. The escalation of public life requires researchers to deepen the work of training specialists in foreign languages. Also, effective teaching of English requires that students communicate as much as possible in English. Naturally, students learn a foreign language mainly in an educational institution, and therefore, the full understanding and application of the teaching lexicon in the educational process is one of the pressing problems. This scientific work, which is designed to show the educational methods and methodological foundations that meet these requirements, is evidence of the relevance of its subject matter.

The aim of the article is that:

- to study and generalize theoretical views by analyzing scientific works on the subject in Uzbek and English languages;

- to identify similarities and differences in the composition of the educational lexicon of the Uzbek and English languages;

- to draw appropriate conclusions from the scientific and theoretical views expressed on the topic, and to approach scientifically;

- characterization of interpersonal situations arising from the interaction of Uzbek and English with the use of the teaching lexicon of these languages; 
- to develop a system of exercises aimed at improving the mastering of the teaching lexicon for the students of the Uzbek audience.

\section{Methodology}

Language is one of the most mysterious and mysterious phenomena of the life of society. The life of a person passes in the language environment, in the world of words. Language surrounds each of us and society as a whole, and at the same time, through society and human consciousness, keeps them in their footsteps. Therefore, a person can not assume himself outside the language. The scientist, who receives through the human eye, ear, body and tongue the ability to perceive, is incredibly narrow and limited, because he sees, perceives, hears all around him. Only with the help of language, we can express our thoughts, our knowledge of the olam. And the language in its place is not only the sum of signs and sounds, but also the sum of words that reflect a certain meaning-essence. Tilni therefore, the importance of lexicology and lexicology as a primary source in learning and teaching cannot be overemphasified.

The dictionary wealth of the language, its application in speech and its functional system have long attracted the attention of linguists and Methodists. Studies on the study of lexicology and lexicology of the language and the formation of pedagogical management in their teaching a number of linguist scientists-J.Buranov, M.Dzhusupov, V.V.Vinogradov, G.B.Antrushina, G.T.It is connected with the names of the cabinet, etc.

Language as a weapon of thought and a means of communication is initially a system of words, in the same word the language expresses its completeness and completeness in the process of interaction of words. In ancient times, people looked at the word as a concept that required a great synergy, an attentive attitude towards oneself. According to the wise men of antiquity, the word creates the perception of a particular person, the purpose of harmony of society and secular order, therefore it is necessary to create and apply it correctly. Despite the fact that the language consists of different units, the word is considered to be one of its most "natural" categories, since it refers to something or expresses it.

The dictionary composition of the language, when pronouns are taken, is called its lexical (in Greek "lexis" - "word"). And the language department, which studies lexicology, its development and functions, is called lexicol ogia. Hence, " lexicology is the science of words or phrases about speech" (Antrushina, 1999:109). Another important aspect of lexicology is the word ma nosidir.So a special section of lexicology, where the meanings of $\mathrm{Zs}$ and the reasons for changing values are studied, is called semasiology (Greek "semasia"- meaning). Lexicology and semasiology are closely related, since the meaning of the word is the word "heart". Since it forms the formal and semantic integrity of the word, it is desirable to describe it in two ways - lexically and semasiologically, without distinguishing it from each other (Girutsky, 2003:109). Lexicology also studies semantic relations and semantic areas such as synonyms, antonyms, homonyms, etc.

The lexicon of the language is studied in several typological groups. C. Buranov distinguished 5 different directions, relying on other scientific sources in the application of lexicology (Buranov, 1990:4):

1. General lexicology is the part of general linguistics that studies the main features of words and the individual signs of words in a particular language. It applies the attributes of words that are inherent in all languages in one way or another. General lexicology refers to the development of dictionary content and the finding of syllables of word samples. Linguistic phenomena and signs inherent in all languages are called linguistic universal.

2. Special lexicology is a part of studying the dictionary composition of a particular language. English lexicology (Ginzburg, 1979), Uzbek lexicology (Hajiyev, 1981), Russian lexicology (Shansky, 1972).

3. Descriptive lexicology studies words from a synchronous point of view. This series of 
lexicology studies and classifies words in the same case, how they are in the same period.

4. Historical or diachronic lexicology studies the development and changes in the composition of the dictionary. For example, words such as "to take", "to adopt" in English, although they seem to be the usual vocabulary, but on historical lexicology they are words that have mastered another language.

5. Comparative or condensed lexicology deals with the classification and comparison of lexical units of two or more languages. For example, RussianEnglish lexicology, English-French lexicology, etc. Other modern sources also differ in the category of theoretical and practical lexicology.

The relationship between the existing words can be either syntagmatic or paradigmatic. Syntagmatic attitude is reflected in the context, and the context becomes the minimum part of speech, from which it is possible to deduce the meaning and essence of the word. For example, take an exam( take an exam), take a break (take a break) is a polysemantic action in word combinations motivated mainly by the context of the meaning of the verb. And the paradigmatic attitude is observed inside the dictionary composition of the word, which is the relationship of words in meaning. Mario Pei quoted in his book" The Story of the Language": "semantics is the appearance of a language with the largest and most extensive coverage. Sounds, words, grammatical forms, syntactic devices are the working instruments of language, and semantics is the recognized purpose of language" (Mario Pei, 1949). According to the paradigmatic connection, words are classified into a group of words with a lot of meanings (polysemantic), meaningful, formative and contradictory meanings. The semantic composition of the lexeme includes lexical meaning, additional ottenka, that is, the edges of the meaning and stylistic SEMAS, the category SEMAS. The lexeme is a thing-the name of an event, an expression, a feature of expression is called its lexical meaning and consists in the interaction between the three phenomena. These include the phonetic form of the lexeme, what is called by the phonetic word-the phenomenon, the predicate, the concept (detonate) and the meaning (significant) formed about the detonate in the human mind. So the phonetic word names the subject, the phonetic word represents the signifier in the human mind, and the semantic unit formed from this connection is considered a lexical meaning. In addition, the lexical meaning also determines the valence of the lexeme, that is, the opportunity to enter into a different degree of connection with other words in the language system. For example, the meanings of book and reading lexemes are dictated by the combination of these two words in speech, but the book and speaking lexemes do not mutually agree because the meanings of both lexemes, the semantic content are not compatible. Lexical meaning is attached by a team of the same language to the phonetic word. Golovin describes the lexical meaning as follows: "what is in existence-events affect our consciousness through our members of intuition, as a result of which the same thing in the human mindthe perception of events, that is, the image remains, the form of the word attached to it in the form of a name, is also reflected in our consciousness (Golovin, 1977: 312). Thus, the constant connection between these two phenomena-the image of the predicate and the image of the word form-will be lexical meaning. The word and its meaning form the concept in the human mind together. So the word can be called the sign of the concept in the language.

Specific cognition means to be skillful in its structure and application of words. For this reason, lexicology and vocabulary of the word are taught in educational institutions as a primary language aspect. And the problem is in the application of what effective techniques to maintain certain types of vocabulary and vocabulary due to the limited number of allocated hours of training. Before talking about the methods of teaching lexicon, it is necessary to first understand the essence and meaning of the subject of methodology. The science of methodology is the science of teaching, which in Greek means "methodize" - "methods of doing something purposefully set ". According to Professor Mikhail Vasilyevich Lyakhovitsky, the methodology of teaching a foreign language is a 
science that studies the goals, content, tools of education, as well as methods of teaching and learning with the help of a foreign language (Lyakhovitsky, 1981:159).

The creation of lexical material that will be introduced into the teaching practice is entrusted to the teaching Methodists, the aim of classifying and presenting them is to form lexical skills in language learners. S.F.Shatilov describes that "lexical skill" is a methodical concept consisting of two parts, that is, the application of a word in speech and the construction of a word in the process of speech (Shatilov, 1977:97). The methodology of teaching lexical material consists mainly of three stages (Jalolov, 2012:158):

1. The presentation of the lexicon is a teacher's explanation for acquaintance with the word, the form, meaning and application of the word.

2. Lexical exercises-the period of application of the familiar lexical in the process of speech, that is, the initial reinforcement of the material.

3. Application of lexicon-the word studied is mastered in the order of skills and qualifications in the types of speech activity.

The purpose of the presentation of the lexicon is to introduce a new word and open the meaning of each word. There are several methods and techniques for explaining the meaning of the word (Jalolov, Makhkamova, 2015:120):

Direct methods: dictionary, synonym, antonym, hyponym (special examples of the general concept), morphological analysis (structure of the word), guessing by context, examples, interpretation, interpretation (without equivalent from the language), adaptation (synonym, antonyms), structural analysis (certain components of the word), compilation of a list of certain words, known or international words.

Visual methods: demonstration in educational apparatus or through drawings on a whiteboard; illustrative material-pictures/ objects, models, movements, mimics, gestures, pictograms, drawings, drawings, schemes.

Method of translation: bring the equivalent, translate-interpretation, compare a foreign word to a native word.
The choice of a successful method of cementing depends on several factors:

- Belonging of the word to the active (productive) or passive (receptive) lexical minimum;

- Educational stage: elementary level-visual techniques, speech samples, translation; secondary level - synonym, antonyms, morphological analysis; Higher Education Level-context, comments;

- demonstration level of students at a certain stage of Education;

- Qualitative characteristics of the word.

The new word can be learned in the case of isolation, that is, either separately or through context. Word single-root nouns, when dealing with Geographical Names; for the development of the ability to guess certain words (the first word is in context, the rest is separate); is used when teaching students to work with dictionaries. It is common for a new word to be used in a contextual position, that is, in a word combination, in a situation, in a story, in the form of a questionanswer, in a speech. And in the later stages, the lexical is strengthened by practice and used in speech.

Mastering the vocabulary of the language is taught in educational institutions on the basis of a traditional system of exercises. These include listening exercises of lexical units, sight-seeing exercises of lexical units, saying and writing exercises of lexical units, prescription and reproductive lexical exercises, etc.

When discussing how to form a lexical skill and its use in speech, it is generally necessary to understand/understand and create, that is, to understand the difference between receptive and reproductive, because in the process of teaching, different techniques are used for both these abilities in the classroom. If the receptive skill dictates the comprehension of the word and the accumulation of it in memory, then with the reproductive ability the reader will take the word out of this memory and apply it in nutshell situations. Many researchers have argued that prescription exercise should be used earlier than reproductive exercise (Asher, 1969; Postovsky, 1974). 
A student learning English has the ability to recognize a dictionary rather than practice words. It is difficult to correctly apply the word in practice. In this case, it will be necessary to be able to correctly pronounce the word, correctly write orthographically, be able to use it in the correct grammar form and adjust to the context. Language is created and developed by society to interact and convey the elements of that language culture. Language as communication always remains a constant participant in society and human activities. Due to this, the science of studying dictionary wealth is closely related to all other aspects of the language (Kabakova, 2012: 114):

a) with phonetics, because the lexical meaning is explained by the phonetic, that is, the units of pronunciation in the language. For example, with short and long vowel sounds (fill - feel); took the language, and the language with medium vowels (bag - beg); with sonorous and sonorous consonant sounds (led-let).

b) morphology: book - books, read-read,

c) syntax: constructive forms;

d) orthography: fair tale-fare tail;

E) Stylistics: friend, pal, teacher, Mrs.Knight

Also, the use of a mountain of Lexicon also dictates other secondary syllables. In the process of speech, formulate the ability to transfer the spoken word from long memory to fast memory. The withdrawal of words from distant memory is carried out by activating the wealth of intelligent words. This activation takes place as the adaptation of words to thought-idea. Sometimes when words corresponding to thoughts are not found, the language becomes the cause of the phenomenon of being at the tip, that is, even if the interpretation of the meaning is necessary, the corresponding form can not be separated from memory. It is also important to check the correct choice of a particular word in a given situation. In this case, an approximate word is used because of the absence of a proportional word in memory or mental reserve. In this case, it attempts to use lexical strategies, such as the use of a word that does not exist in the language, the use of a different way of expressing an opinion, the use of a word that does not exist in the language, or the construction of a word other than the lexical known to the speaker, the mimicry and gestures. It is also necessary to take into account that with other lexical units in the colloquial language the word quickly acquires unity. Cognitive process creates the meaning that a person wants to put into circulation in a situation. In order not to provoke an unfavorable situation or a negative reaction in circulation with other participants, it is necessary to take into account the word pragmatics. The use of the word means that it is able to understand certain grammatical norms and rules. Finally, the word comes to life in memory and is created in a graphic or verbal form. Dictionary wealth of language can be relatively complex, neutral or simple for learners. The choice and creation of teaching material taking into account the specific class, level, conditions and skills of mastering is one of the tasks of each teacher. There are a number of ways to understand the degree of complexity of lexical units. It takes into account the qualitative characteristics of words, that is, the formal, functional and semantic features of a given word and the degree of their similarity according to the state of the connected languages. The choice of words that people use in oral and written speech will depend on the situation in which they fall. The diversity of the language used in the case of communication is called the language style, and if an informal style is used between close friends and acquaintances, the formal style with business partners, providing a neural style and work, is suitable for young people. Language users tend to switch dictionary units when communicating with professionals or nonprofessionals, adolescents or children, indifferent or impulsive people. The choice of dictionary units to achieve the best communication goal is called "language list" (language register) (Milrud, 2007:93). It is also taken into account the quantitative features of the words, the use of the word as a metaphor, the phenomenon of polysemia, the length of the words on the basis of letters or syllables.

In order to store and use new words in memory, associative communication is of great importance. 
There are the following types of associative Communication Unit: 1. Synonyms; 2. Antennas; 3. Shy concepts: table-chair (furniture); 4. Meaning: table-furniture; 5. Connection of concepts: pupil-class (whole and part connection), causality - death (cause and effect).

The successful outcome of the formation of pedagogical management for the teaching of vocabulary wealth is primarily due to the correct sorting of lexical minimums. In principle, it focuses on two issues: the interpretation of the concept and the selection criterion. When we say the principle of selection, we understand the norm of the indicators by which the evaluation of the lexicon is organized. Depending on the specifics of these indicators, all principles are divided into related groups (Jalolov, Kabarova, 2015:118).

1. According to statistical principles:

- frequency (the total amount of word repetition in the source);

- scale (match the word in different texts)

2. According to methodological principles:

- thematic (depending on the topics given in the action plan);

- semantic (words that reflect the basic concepts of the subject or situation);

- ability to master ( orthographic, phonological challenges, syntactic features, paronyms, cultural aspects)

3. According to linguistic principles:

- get someone;

- word build value;

- polysemantic words;

- methodical freedom.

Methodological preparation of the new lexical takes place in the static and dynamic stages. Active or productive lexical is used in oral speech, and passive or receptive vocabulary is used in written speech.

Programming requirements for the teaching of lexical material require the development of special methodical principles. $\mathrm{V}$ in this regard.A. Buhbinder passed the following principles (Buhbinder, 1972 :449):

1. The principle of rational limitation of the dictionary in teaching a foreign language: the composition and nature of the them selection units are determined strictly; selection criteria serves to take into account the full characteristics of lexical units; selection units are coordinated by the criteria. 2. The principle that the presentation of lexical units in Language Teaching is aimed at a particular purpose: the units used to reinforce the lexical operation are intended to form a specific skill and are used in harmony with other units.

3 . The principle of taking into account the linguistic features of lexical units and the psychological nature associated with their assimilation: in the periods of presentation and exercise, the lexical units are given in the context by means of a description of what they express consciousness, those belonging to things with the help of blindness, and those words that form a system.

4. The principle of taking into account the didactic and Psychological Laws of education: each lexical unit is taught progressively at the stages of presentation, exercise and application, that is, it is taught consistently that it is used in the context, as well as in groups, in the framework of meaning, sound and writing symbols and in various combinations.

5. The principle of interdependence in the provision of real dictionary wealth, interpretation of the meaning of a new word, and the formation of the dictionary: all three tasks are active, interrelated and consistently carried out.

6. The principle of relying on semantic generalization: by analyzing the composition of the lexical unit of content, it is achieved to determine the signs of similarity and discrepancy between the units and the semantic variants of a multi-meaning unit. Such an event will open the meaning of the word and, consequently, facilitate the appropriate application and correct understanding of lexical unity in the speech of students.

7. The principle of improving speaking skills and accompanying the acquisition of Lexicon in this process: the process of mastering the lexicon implies the acquisition of material and the development of skills.

8. It is necessary to repeat the word as much as possible and achieve compound with other words. 
9. The level of knowledge/possession of lexical units is controlled not by a separate examination method, but by the process of application in speech. 10. In teaching many meaningful words, the current lesson is limited to one meaning.

11. In addition to the dictionary minimum, the teacher carefully approaches the teaching of words.

The task pursued by the educational goals is to achieve the level of application of the lexicon, which is considered the final work of the process of teaching foreign language lexicon in the sphere of skills generation. The term of application expresses the meaning of the word coming in reproductive and receptive speech.

When it is said to apply" statement of opinion "is kept in sight, while the concept of" recognition "is associated with" perception of speech by another person". In short, when we say application, it is understood that the unit of language is also used in the Quaternary type of speech activity.

Teaching lexicon of English and Uzbek languages: general and different aspects

The personality of a person is formed and develops under the influence of various forces and conditions: objective and subjectively, natural and social, internal and external, independent and selfreliant on the Will and consciousness of people who act according to their own or specific goals. At the same time, the role of pedagogical influence is undoubtedly one of the leading factors in the development of the negation of the worldview, the perception of the worldview and the strengthening of a person's understanding. (Kurovskaya, 2014: 2) for this reason, the importance of the English language learning lexicon is paramount to ensure the success of the lesson and to ensure that learners are able to enter into full foreign language communication at the lesson.

Linguistics department is engaged in the study of linguistic units of the English and Uzbek languages by comparing them. Shcherba L. with the field of condensed linguistics and lexical typologyV., Stepanova M.D., Gaplerin I.R, Nikonov V.A., Dzhusupav M., Buranov J. like linguists and Methodist scientists are engaged.
The main informative part of all the special lexicon is terminology. A significant feature of the special lexical, according to the researchers, is the character of lexical units in communication with concepts and naming entities. In words of special lexical composition, either concepts (terms, nomenclature) or predicate relation (for example, personal names, commercial nomenclature) prevail (Dzhusupov, 2013:17). Many linguists believe that the term is two-sided: either as a dictionary unit belonging to the lexical system of the language, or as a logo representing a certain scientific concept. Its belonging to a special lexicon is an exact attribute. Linguistic norms of the special lexicon are necessary in proportion to the norms of the general literary language, in the same period there are relative requirements of the terming: one meaningfulness, accuracy, motivation, systematic.

The main task of lexical typology is to compare the units of the lexical layer of the language. Lexical typology considers the interlingua paradigms of words, the interlingua invariants of the meaning expressed by verbal units. Dictionary typology includes the following sections and aspects:

1. Lexical typology of the word or typology of words;

2. Lexical typology of word combinations;

3. Lexicography of dilution;

4. Lexical-statistical typology;

5. Lexical typology of words mastered from another language;

6. Phraseology is that lexical typology of phrases;

7. Lexical typology of Proverbs and aphorisms;

8. Onomastics, that is, the lexical typology of patronymic names;

9. Toponym, that is, lexical typology of the names of place-space;

10. Lexical typology of terminology;

11. Diachronic lexical typology;

12. Synchronic lexical typology. Zire " lost in Test match)

Teaching lexicon means material objects used in the classroom, lexical units related to education in teacher and learner communication, textbook, teaching instructions are understood. English and 
the teaching lexicon differ from each other and at the same time, mainly due to the specific lexicalgrammatical features of the languages, the educational system of the states and the culturalspiritual characteristics of classroom management, activities and design.

When classifying words from different points of view: in the lexical-grammatical category (word categories), according to the methods of making words (simple, joint, derivative), according to the task (independent and Auxiliary), the subject and group of terms, the semantic circle, etc. are taken into account.

The external world is formed in the form of symbols of something and words in the human mind. As a second signal system, the word provokes the embodiment of a predicate and an event, for example, when we hear or read the word "teacher" before our eyes "school" or "lesson process" is shaken.

The structure of the language lexical is represented by language tools of different language hierarchies. The most basic of them are these lexical - semantic and syntactic stages.

1. Each lexical-grammatical category is grouped into words made from the core word, the derivative word, complex and complex. This classification can be observed in both languages, even if the Uzbek (agglutinative) and English (flektiv) belong to a different morphological type. In both languages, the word-building suffix, attaching to the root morpheme, forms a word with a new lexical meaning.

Graph № 1

\begin{tabular}{|c|c|c|}
\hline & English & Uzbek \\
\hline Core word & $\begin{array}{l}\text { Book; desk; } \\
\text { grade }\end{array}$ & $\begin{array}{l}\text { Kitob; parta; } \\
\text { baho }\end{array}$ \\
\hline Morphology & $\begin{array}{l}\text { Graduation; } \\
\text { teacher; } \\
\text { lecturer; ruler }\end{array}$ & $\begin{array}{l}\text { Bitiruv; } \\
\text { o'qituvchi; } \\
\text { ma'ruzachi; } \\
\text { chizg'ich }\end{array}$ \\
\hline Com & $\begin{array}{l}\text { Bookshelf; } \\
\text { timetable }\end{array}$ & $\begin{array}{l}\text { Kitob javoni; } \\
\text { dars jadvali }\end{array}$ \\
\hline $\begin{array}{l}\text { Complex word } \\
\text { formation }\end{array}$ & $\begin{array}{l}\text { Pencil } \\
\text { sharpener }\end{array}$ & $\begin{array}{l}\text { Qalam } \\
\text { yo'ngich }\end{array}$ \\
\hline
\end{tabular}

The grammatical - lexical structure of most words in English and Uzbek is not suitable: poster plakat; notebook - daftar; textbook - darslik; paint - bo'yoq.

The analysis revealed that the following verbs are widely used in the legislative and complex legislative words contained in the teaching lexicon in asosisa English: - er (cassette -recorder), -ium (auditorium, gymnasium), -ant (attendant, participant), - or (overhead projector, protractor, calculator), -(o)logy (linguoculturology, sociology); -ics (linguistics); - ion / -tion (education, permission); - ce (absence, attendance); - ary (elementary, secondary); - ize (memorize, dramatize); re- (rewrite, reproduce); ify (intensify, classify); -(a)tive (declarative, affirmative).

In the Uzbek language, such verbs are as follows: -iq (topshiriq); -la (sharhlamoq, so'zlamoq, takrorlamoq); - xona (sinfxona, kutubxona); -(g')ich (chizg'ich, o'chirg'ich), (v)chi (o'quvchi, o'qituvchi, ma'ruzachi); -iy (ilmiy,nutqiy) -(u)v (yozuv, chizuv), - ish (tuzilish).

Without the above suffixes completely change the semantic meaning of the word, the suffix core word makes up the word in the new word category. Complex compound words belong mainly to the category of NOUN, noun+noun or noun+verb (+suffix) is formed from the components pencil sharpener - qalam yo'ng'ich; modal verb - modal fe'l.

In English, the compound verbs (phrasal verbs) in the composition of the instrumental verbs, which are most often used in training, also form the plural part, they are formed in the form of the preposition copy out - yozmoq; make up - tuzmoq; find out topmoq; substitute for - ekvivalenti bilan almashtirmoq.

Verbs in the Uzbek language are formed in the form of a noun+verb: translate, memorize, analyze, pay attention, exercise, continue.

In the English Language Teaching lexicon there are lexical units (idioms), which find content from several independent and auxiliary words and 
express the same meaning: learn by heart memorize; skip classes - learn.

\section{Conclusion}

In our country, the government is carrying out extensive work to further improve the sphere of teaching foreign languages, to increase the literacy of the population in terms of language, to bring the Uzbek name to the world, to learn a foreign language. Today, scientific work is being created to produce and implement more effective methods of teaching a foreign language, especially English, and the scientific and practical base of foreign language teaching methodology is being replenished. In the same science itself, the attitude to language has changed, instead of the idea of learning, the idea of mastering appeared. This in turn led to the emergence of new methods and approaches in the methodology of teaching foreign languages.

To ensure the success of the lesson and to ensure that learners can access full foreign language communication in the lesson, the importance of the English language learning lexicon is paramount. Lexicon is of great importance as an object of methodology, and its teaching is carried out mainly in three stages:

1. The presentation of the lexicon is a teacher's explanation for acquaintance with the word, the form, meaning and application of the word.

2. Lexical exercises-the period of application of the familiar lexical in the process of speech, that is, the initial reinforcement of the material.

3. Application of lexicon-the word studied is mastered in the order of skills and qualifications in the types of speech activity.

Teaching foreign languages process the formation of communicative competence in students is the main goal of today's methodology. And communicative competence, in turn, includes several small compensations, and the first of them is linguistic competence. When it comes to linguistic competence, it is understood that the student has excellent knowledge and skills in English Vocabulary. Mastering the vocabulary of the language is taught in educational institutions on the basis of a traditional system of exercises. These include exercises to listen to lexical units, exercises to see lexical units, exercises to say and write lexical units, prescription (passive) and reproductive (active) lexical exercises, etc.

Relatively difficult and the most difficult lexical units make up the content of teaching vocabulary. When we say the meaning of teaching lexicon, because of its difficulty, words that require special exercises and are taught by interpretation, form a certain shortening of the lexical minimum are understood. Difficulty is observed in the form, meaning or application of the word. Consequently, the word can be functional, semantic, formally difficult, or one of them is either two, or even three sides difficult.

As it turned out from the exposition, the level of mastering of the English Language Teaching lexicon of students in the Uzbek audience is not satisfactory $(63,4 \%)$. In overcoming this issue, it would be worthwhile to give more confidence to the organization of training hours devoted to the English Language Teaching lexicon. In the abovementioned teaching aids, little importance is attached to the teaching lexicon of the English language. To eliminate this problem, the body needs to create a special system of lexical exercises.

From the practical analysis of the constructive part came the following conclusions:

- The need for systematic sorting of lexical material;

- The need to attach lexical and material to the English language teaching process;

- To develop a system of scientifically based exercises for Uzbek students to improve their knowledge of the concepts of the lexical layer on the teaching lexicon of the English language and to prevent interpersonal situations in speech.

- In accordance with the state standard of education and the knowledge base of the students, exercises of difficulty corresponding to the B2 level were given.

- As much as possible, the contexts inherent in the English and Uzbek culture were chosen and introduced into the exercises. 
The principle of complex organization of the educational process provides for the organization of speech activities in various forms by linking phonetic, lexical, grammatical material. The complex organization of the educational process requires the joint implementation of educational goals (practical, educational, educational, developmental).

Such exercises are practical exercises aimed at further enriching the vocabulary in the English Language Teaching and learning system of firstyear students, forming lexical skills, transferring it from temporary memory to permanent memory. Despite the fact that some of the lessons are relatively complex, they are able to give students the ability to work with dictionaries, to understand them through context.

In summary, an exercise system should be structured to study every English language learning lexical work. Exercises can be created differently and with different difficulty, based on different styles. However, according to the recommendations in this scientific work, it is worthwhile to create exercises based on a communicative approach, covering the contexts inherent in different mother tongue and foreign language. The main thing is that when solving exercises, students should not suffer from interpersonal situations by comparing lexical units of English and Uzbek languages. This is evidenced by the fact that the system of exercises and textbooks should be rich in assignments, which also include the analysis of the mother tongue and foreign language in the study.

\section{References}

[1] Antrushina G.B., Afanas'eva O.V. Lexicology of the English language. - M: "Bustard", 1999. - p. 109

[2] Arakin V.D. Peasant. Practical English course. 1 course. - "Humanitarian Publishing House of Saint Vlados", 1999.

[3] Beldiyan V.M. Linguodidactics and its requirements for building a system of exercises. - In the book; Problems of Russian linguodidactics in the national university: Sat. scientific. tr. Ed. N.M. Shansky and G.G. Gorodilova - M., 1981 pp. 39-50.

[4] Buranov D.Zh. Comparative typology of English and Turkic languages. - M: "Hanging School", 1983.

[5] Buchbinder V.A. Fundamentals of teaching vocabulary in high school (based on the German language): Author's abstract. doct. diss. - M., 1972 - pp. 449 - 462.

[6] Weinreich U. Jazikovie contacts. Research status and problems. Kiev, 1979, - p. 264.

[7] Girusky A.A. Introduction to linguistic knowledge: textbook. help. - M: "TetraSystems", 2003. - p. 109

[8] Golovin B.N. Introduction to linguistic knowledge. - M: "Hanging school", 1977 $312 \mathrm{p}$.

[9] Dadajanova IB Comparative analysis of demographic vocabulary in English and Tajik languages: Abstract. - Dushanbe 2011. - p. 22 - 23.

[10] Danchinova M. Yu. Significance of interference in the study of a foreign language // All-Russian scientific and methodological conference November 10, 2013 - January 30, 2014 "Pedagogical technology and teacher skill". - 2014.

[11] Dzhusupov M. Sound systems of Russian and Kazakh languages. Syllable. Interference. Learning pronunciation. -T .: Fan, 1991 .-p 239.

[12] Dzhusupov M. Linguodidactics and methodology in the polyscientific system of language education. // Russian language abroad, 2009, No. 2. - p. 26-32.

[13] Dzhusupov M. Special vocabulary and proverbs (Linguistic contrast and methodological aspects). - Tashkent: "Merius", 2013. - 17 p.

[14] Karimov I.A. Uzbekiston XXI asr by̆sagasida: havsizlikka tagdid, barkarorlik shartlari va tarakkiyot kafolatlari. Toshkent: Uzbekiston, 1997, 150 p.

[15] Karimov I.A. Tarikhiy hotirasiz kelajak yy̆k. - T .: Shark, 1998, - 35 p. 
[16] Karlinsky A.E. Foundations of the theory of language interaction. -Alma-Ata: Galim, 1990.- p. 181.

[17] Kurovskaya. SOUTH. Academic Vocabulary from the Point of View of the Frame Approach - 2014.

[18] Lvov M.R. Dictionary-reference book on the methodology of the Russian language. M., 1988.

[19] Lyakhovisky MV Methods of teaching foreign languages: [Textbook. manual for filol. arrogance. universities] - $\mathrm{M}$ : "Hanging school", 1981 - 159 p.

[20] Mirolyubov A.A. Methodology or linguodidactics of foreign languages. Foreign languages at school. 2005. № 2.

[21] Passov E.I. The basics of the communicative method of teaching foreign communication. - M., Russian language 1989, - p. 144-145. 